\title{
Sulphuric Acid Resistant of Self Compacted Geopolymer Concrete Containing Slag and Ceramic Waste
}

\author{
I. Shafiq ${ }^{1, *}, M$. Azreen $^{2}$, and $M . W$. Hussin $^{1}$ \\ ${ }^{1}$ Faculty of Civil Engineering, Universiti Teknologi Malaysia, 81310 UTM Johor Bahru, Johor, \\ Malaysia. \\ ${ }^{2}$ Forensic Engineering Centre, Institute for Smart Infrastructure Innovative Construction, Faculty of \\ Civil Engineering, Universiti Teknologi Malaysia, 81310 UTM Johor Bahru, Johor, Malaysia.
}

\begin{abstract}
Malaysia is a one of the developing countries where the constructions of infrastructure is still ongoing, resulting in a high demand for concrete. In order to gain sustainability factors in the innovations for producing concrete, geopolymer concrete containing granulated blastfurnace slag and ceramics was selected as a cement replacement in concrete for this study. Since Malaysia had many ceramic productions and uses, the increment of the ceramic waste will also be high. Thus, a new idea to reuse this waste in construction materials have been tested by doing research on this waste. Furthermore, a previous research stated that Ordinary Portland Cement concrete has a lower durability compared to the geopolymer concrete. Geopolymer binders have been reported as being acid resistant and thus are a promising and alternative binder for sewer pipe manufacture. Lack of study regarding the durability of the geopolymer self-compacting concrete was also one of the problems. The waste will be undergoing a few processes in the laboratory in order to get it in the best form before undergoing the next process as a binder in geopolymer concrete. This research is very significant in order to apply the concept of sustainability in the construction field. In addition, the impact of this geopolymer binder is that it emits up to nine times less $\mathrm{CO}_{2}$ than Portland Cement.
\end{abstract}

\section{Introduction}

Higher demand for concrete from the construction field has almost peaked in every country in the world including Malaysia that is developing country, leading to the search for a new solution that focuses more on recycle and reuse of waste product in order to generate new construction material that can achieve a sustainable concept [1].

OPC production is considered an environmental problem because it requires large quantities of raw materials and fuel and contributes $8 \%$ of global $\mathrm{CO}_{2}$ emission $[2,3]$. Furthermore, OPC is not chemically stable, deteriorates through sulfate, sulfuric acid

*Corresponding author: mohdazreen@utm.my 
attacks and elevated temperature exposure $[4,5]$. The use of pozzolon to replace part of OPC has become more attractive and important. Geopolymers (GP) are one of the alternatives to overcome all these issues [6].

Previous research has shown that OPC concrete has a very low durability against sulphuric acid attack compared to the geopolymer concrete [7]. Durability refers to the ability of concrete to resist deterioration from the environment or service in which it is placed. Properly proportioned concrete that is properly placed, finished, and cured should endure without significant distress throughout its service life [8]. This is because the penetration of sulfates in solution causes change in the composition and microstructure of the concrete. These changes may vary in type or severity, but commonly include extensive cracking, expansion and loss of bond between the cement paste and aggregate. Alteration of paste composition results in monosulfate phase converting to ettringite and, in later stages, gypsum formation. The necessary additional calcium is provided by the calcium hydroxide and calcium silicate hydrate in the cement paste. The effect of these changes is an overall loss of concrete strength [9].

In addition, geopolymer binders have been reported as being acid resistant and thus are a promising alternative binder for sewer pipe manufacture compared to Ordinary Portland Cement Concrete [10]. Lack of study about high strength of self-compacting geopolymer concrete against sulphuric acid attack is also one of the problems. The previous research studied the normal strength of self-compacting geopolymer concrete.

In this research, slag and ceramics will be used as the replacement to OPC. Slag contains high calcium, which is suitable for aggressive environment [11], while the ceramic that contain high silica can make the concrete more durable and more binder gel [12]. There is also pressure to provide a better quality concrete to the construction sector and to preserve natural resources and the air quality, and it is expected that this geopolymer selfcompacting concrete (GSCC) can solve all the issues described in OPC [13].

The aim of this research is to study the durability of self-compacting geopolymer concrete against sulphuric acid attack which mainly use Ground Granulated Blast-Furnace Slag (GGBFS) and Ceramics waste as a binder. In order to achieve this aim, several objectives are identified and measured to ensure that the fundamental parameters needed in the design are evaluated. These parameters include determining the optimum mix design for geopolymer concrete containing Granulated Blast-Furnace Slag and Ceramics as a binder, the durability performance of Granulated Blast-Furnace Slag and Ceramics concrete against sulphuric acid attack and the effect of geopolymer concrete after immersion in sulphuric acid solution.

This research has been carried out to investigate the durability performance of Granulated Blast-Furnace Slag and Ceramics concrete against sulphuric acid attack. The specimens were prepared in $100 \mathrm{~mm} \times 100 \mathrm{~mm} \times 100 \mathrm{~mm}$ cubes. Type of curing for this concrete was ambient temperature. Compressive strength test is conducted to study the engineering properties of slag concrete. The cubes have been tested for compressive test after being immersed in sulphuric acid solution for 28 days or more. The concentration of sulphuric acid solution has a $\mathrm{pH}$ of 3.0.

\section{Methodology}

\subsection{Preparation of materials}

Materials used in this research basically consist of Granulated Blast-Furnace Slag, Ceramics, fine (Sand) and coarse aggregates (Gravel 10mm) and alkaline solution. The 
grading of the fine and coarse aggregates followed the ASTM standard C33 (Standard Specification for Concrete Aggregates) [14].

The Granulated Blast-Furnace Slag was collected from slag factories in parts of southern Malaysia while the ceramic waste was collected from a ceramic factory. After collection, the ceramic will be crushed by a crusher jaw to make it smaller and easier to sieve. The ceramic waste that has been crushed will then be sieved by a mechanical sieve shaker for a sufficient period and will be grounded in Los Angeles Abrasion Machine for at least 8 hours for each $4 \mathrm{~kg}$ using a steel bar of $18 \mathrm{~mm}$ in diameter and $800 \mathrm{~mm}$ long. Only the finest ceramic will be used in the mixing. Then the fine ceramic will be kept tightly secured in a container. The coarse aggregates, which are gravel, were collected from the Structure and Materials Laboratory at Universiti Teknologi Malaysia (UTM), Malaysia. The gravel will be sieved by a mechanical sieve shaker and only the gravel that passed through $10 \mathrm{~mm}$ sieve were collected and used in the mixing.

For the alkaline solution, $8 \mathrm{M}$ and $12 \mathrm{M}$ of sodium hydroxide and sodium silicate were used because previous research stated that $8 \mathrm{M}$ of $\mathrm{NaOH}$ has a better workability compared to $12 \mathrm{M}$ of $\mathrm{NaOH}$ [15]. Davidovits (2002) suggested that it is preferable to mix the sodium silicate solution and the sodium hydroxide solution together at least one day before adding the liquid to the solid constituents [16].

\subsection{Mix Design}

\subsubsection{Cube Sample}

The mix proportion of this geopolymer self-compacting concrete was shown in Tables 1 and 2 for the control sample mix proportion.

Table 1. Mix Proportion of GSCC.

\begin{tabular}{|c|c|c|c|}
\hline & Slag(kg) & Ceramic(kg) & F.A(kg) \\
\hline GSCC & 1.8 & 1.8 & 2.58 \\
\hline C.A (kg) & SP(kg) & $\mathrm{Na}_{2} \mathrm{O}_{3} \mathrm{Si}(\mathrm{kg})$ & $\mathrm{NaOH}(\mathrm{kg})$ \\
\hline 1.11 & 0.26 & 1.18 & 0.47 \\
\hline
\end{tabular}

\begin{tabular}{|c|}
\hline $\begin{array}{c}\text { Extra } \\
\text { Water(kg) }\end{array}$ \\
\hline 0.41 \\
\hline
\end{tabular}

Table 2. Mix proportion of OPC concrete.

\begin{tabular}{|l|c|c|c|c|c|}
\hline & W/B ratio & $\begin{array}{c}\text { Water } \\
\left(\mathbf{k g} / \mathbf{m}^{\mathbf{3}}\right)\end{array}$ & $\begin{array}{c}\mathbf{O P C} \\
\left(\mathbf{k g} / \mathbf{m}^{\mathbf{3}}\right)\end{array}$ & $\begin{array}{c}\mathbf{F A} \\
\left(\mathbf{k g} / \mathbf{m}^{\mathbf{3}}\right)\end{array}$ & $\begin{array}{c}\mathbf{C A} \\
\left(\mathbf{k g} / \mathbf{m}^{\mathbf{3}}\right)\end{array}$ \\
\hline $\mathrm{OPC}(100 \%)$ & 0.59 & 192 & 384 & 898 & 861 \\
\hline
\end{tabular}




\subsubsection{Testing procedure of GSCC}

In this research, the slump flow and L-Box test were performed to ascertain the selfcompacting capabilities. All those tests are in accordance with European Federation of National Associations representing producers and applicators of specialist building products for Concrete (EFNARC) guidelines [17]. The slump flow test was used to assess the horizontal free flow of SCC in the absence of obstruction. On lifting the slump cone filled with concrete, the concrete begins to flow. The time $T_{50 \mathrm{~cm}}$ is a secondary indication of flow. It measures the time taken in seconds from the instant the cone is lifted to the instant when horizontal flow reaches a diameter of $500 \mathrm{~mm}$.
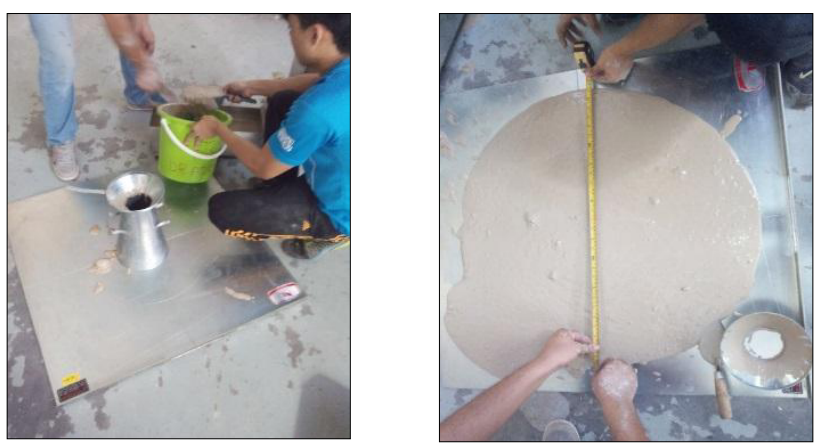

Fig 1. Procedure for Slump-Flow Test.

The passing ability is determined by the L-box test as shown in Figure 2. The vertical section of the L-box is filled with concrete, and then the gate lifted to let the concrete flow into the horizontal section. The height of the concrete at the end of the horizontal section is expressed as a proportion of that remaining in the vertical section $\left(\mathrm{H}_{2} / \mathrm{H}_{1}\right)$. This is an indication of passing ability.
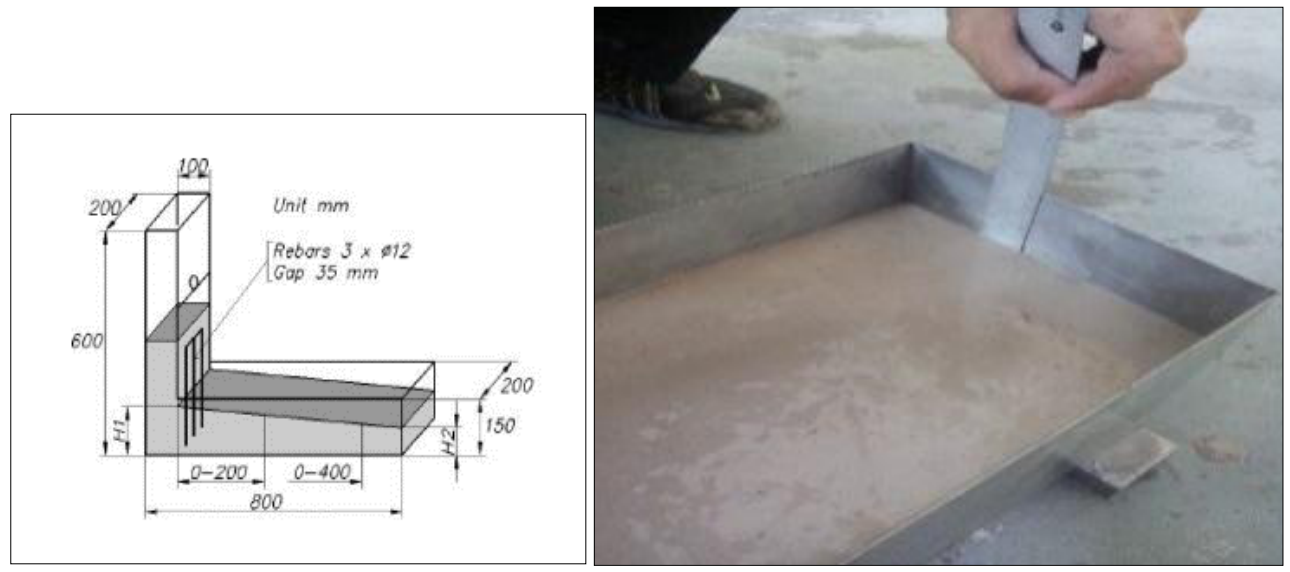

Fig 2. Procedure for L-Box. 


\section{Results}

In this chapter, all $100 \mathrm{~mm} \times 100 \mathrm{~mm} \times 100 \mathrm{~mm}$ samples are used for compressive testing. These results were presented in the form of table, graph and images where all comparisons of the results will be shown. In addition, the test methods for self-compacting, which is Slump flow, $\mathrm{T}_{50 \mathrm{~cm}}$ slump flow and L-box will be shown, including the results.

\subsection{Compressive Test}

The most valuable concrete property is the concrete compression strength because it gives the overall definition of the quality of concrete in terms of concrete strength in relation to the hydrated cement paste. Only compressive testing of the hardened concrete has been conducted. For the compression test, $3.50 \mathrm{~N} / \mathrm{mm}^{2}$ was set according the laboratory standard [14].

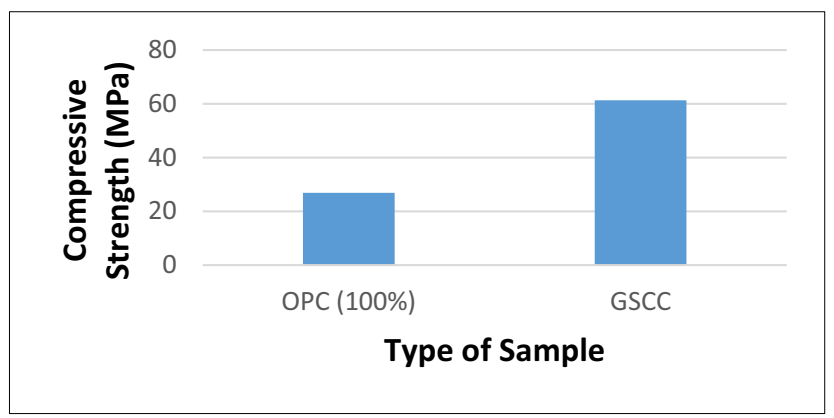

Fig 3. Compressive Strength against Type of Sample.

From Figure 3, it can be seen that Geopolymer Self-Compacting Concrete blended with slag $(50 \%)$ and ceramics $(50 \%)$ have a higher compressive strength than normal concrete (100\% OPC). The strength improvement of Self-Compacting Concrete blended with slag contributed to the early strength of a concrete, thus making the concrete more durable and better than normal SCC (100\% OPC). Also, it is clear that the role of slag and ceramics that contain high calcium and silica increase the compressive strength of the concrete.

\subsection{Testing for Self-Compacting Concrete (SCC)}

A concrete mix can only be considered as SCC if the three characteristics for workability are satisfied [17]. The three fresh concrete characteristics mandatory for SCC are filling ability, passing ability and resistance to segregation. Only Slump flow test, $\mathrm{T}_{50 \mathrm{~cm}}$ slump flow and L-box test have been conducted.

\subsection{Fresh Properties of GSCC}

The slump flow values of SCC with slag and ceramics are shown in Table 3. From the results, the slump flow values were calculated at $780 \mathrm{~mm}$. According to the values recommended by EFNARC for fresh state properties of SCC, the mixtures fulfilled the filling ability.

The L-box test results are shown in Table 3. From the results, the blocking ratio for trial 6 is 1.0. A satisfactory blocking ratio was observed for this GSCC (50\% slag and $50 \%$ ceramics). In a previous study, Felekoglu et al. concluded that a blocking ratio of 0.6 to 1 is 
acceptable for SCC to obtain the satisfactory filling ability. In this regard, this concrete mix was satisfactory.

Table 3. Workability Test Results.

\begin{tabular}{|c|c|c|c|}
\hline $\begin{array}{c}\text { Workability } \\
\text { Test }\end{array}$ & $\begin{array}{c}\text { Slump } \\
\text { Flow Test } \\
\text { (mm) }\end{array}$ & $\begin{array}{c}\mathbf{T}_{\mathbf{5 0 c m}} \\
\text { slump } \\
\text { flow (sec) }\end{array}$ & $\begin{array}{c}\text { L-Box } \\
\left(\mathbf{H}_{\mathbf{2}} / \mathbf{H}_{\mathbf{1}}\right)\end{array}$ \\
\hline GSCC & 780 & 4 & 1.0 \\
\hline
\end{tabular}

\subsection{Durability test for sulphuric acid}

It is accepted that concrete is not fully resistant to acids. All acids will have an impact on concrete. The rate of speed of action may differ, but they finally disintegrate the concrete. Six cube specimens of size $100 \mathrm{~mm} \times 100 \mathrm{~mm}$ x100 mm were prepared and immersed in sulphuric acid solution ( $\mathrm{pH} 3$ ) for 28 and 42 days.

\subsubsection{Compressive strength comparison between OPC concrete and Geopolymer concrete after acid immersion after 28 and 42 days.}

Figure 4 shows the compressive strength comparison between OPC concrete and geopolymer concrete (GSCC) after acid immersion for 28 days. GSCC has a better strength compared to the OPC concrete after 28 and 42 days. The high percentage of calcium in the geopolymer binder (slag) produces a better concrete in terms of durability and strength. The composition and microstructure of the OPC concrete have changed due to the penetration of sulfate in the sulphuric acid solution, thus gypsum is formed. The effect of these changes is an overall loss of concrete strength.

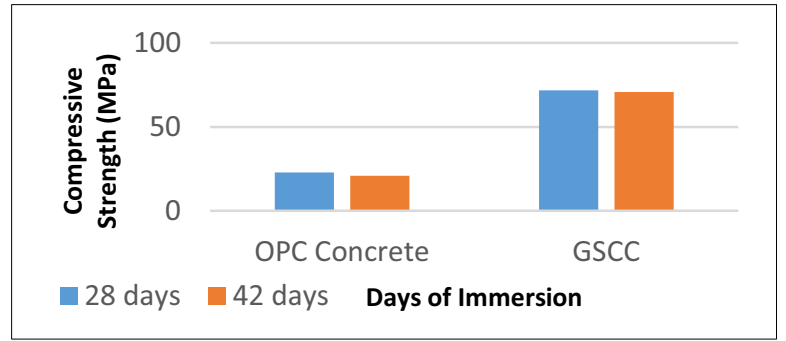

Fig 4. Compressive Strength against Days of Immersion.

\section{Conclusion}

All conclusions drawn upon here are based on the objectives of the study and observations done throughout the whole course of this study. The conclusions that can be drawn in studying geopolymer self-compacting concrete against sulphuric acid attack are that the most optimum mix design for granulated blast furnace slag and ceramic powder as a cement replacement is $50 \%$ for slag and $50 \%$ for ceramic powder. In addition, $8 \mathrm{M}$ of Sodium Hydroxide $(\mathrm{NaOH})$ gives a better workability as compared to $12 \mathrm{M}$ of Sodium Hydroxide $(\mathrm{NaOH})$. Slag also has a low workability because it has a low relative density that causes an increase in paste volume. Thus, more water is needed for the self-compacting 
concrete, which can lead to low compressive strength. Lastly, the sulphuric acid solution had no effect on the strength of the concrete and the weight after being immersed in sulphuric acid solution for 28 and 42 days.

The authors would like to acknowledge UTM for providing the Research University Grant (RUG), VOT No.Q.J130000.2522.13H01 from Ministry of Education (MOE) of Malaysia for the financial supports.

\section{References}

1. Tarun R Naik, Rakesh Kumar. Third International Conference on Sustainable Construction Materials and Technologies 1 (2013)

2. K.L.Scrivener, R.J. Kirkpatrick, Cem. Concr. Res. 38, 128 (2008)

3. J.G.J. Olivier, G.Janssens-Maenhout, J.A.H.W. Peters, Trends in global $\mathrm{CO}_{2}$ emissions report (Rep., PBL Neth. Environ. Assess. Agency, The Hague, 2012)

4. M.A.M Ariffin, M.A.R. Bhutta, M.W. Hussin, M. Mohd Tahir, Nor Aziah, Constr. Build. Mater. 43, 80 (2013).

5. M.W. Hussin, M.A.R Bhutta, M. Azreen, P.J. Ramadhansyah, J. Mirza, Materials and Structures 48, 709 (2015)

6. P. Duxson, J.L. Provis, G.C. Lukey, J.S.J Deventer, Cem. Concr. Res. 37, 1590 (2007)

7. H.S. Shankar, R. B. Khadiranaikar, Journal of Civil and Structural Engineering 3, 396 (2012)

8. Peter Taylor, Durability of Concrete. Transportation Research Board of the National Academies (2013)

9. C.F. Ferraris, P.E. Stutzman, K.A. Snyder, Sulfate Resistance of Concrete: A New Approach, R\&D Serial No. 2486, Portland Cement Association (Skokie, Illinois, USA, 2006)

10. X.J. Song, M. Marosszeky, M. Brungs, R. Munn, 10DBMC International Conference On Durability of Building Materials and Components (Lyon, France, 2005)

11. Md. Moinul Islam, Md.Saiful Islam, Bipul Chandra Mondal, Mohammad Rafiqul Islam, Journal of Civil Engineering (IEB) 38, 129 (2010)

12. Paratibha Aggarwal, Rahul Pratap Singh and Yogesh Aggarwal, Civil and Environmental Engineering 2, 1 (2015)

13. Srinivas Vasam, K. Jagannadha Rao, M.V. Seshagiri Rao. International Journal of Research in Engineering and Technology 4, 1 (2015)

14. American Society for Testing and Materials, Standard Specification for Concrete Aggregates (ASTM C33 - 03)

15. M. Fadhil Nuruddin, Samuel Demie, M. Fareed Ahmed, Nasir Shafiq, International Journal of Civil and Environmental Engineering 3, 122 (2011)

16. P. Ganapati Naidu, A.S.S.N. Prasad, S. Adiseshu, P.V.V. Satayanaraya. International Journal of Engineering Research and Development 2, 19 (2012)

17. European Federation of national trade associations representing producers and applicators of specialist building products, Specification and Guidelines for selfcompacting concrete (Hampshire, U.K, 2002) 